\title{
Effect of progesterone and first evidence about allopregnanolone action on the progression of epithelial human ovarian cancer cell lines.
}

Key words:

Proliferation

Clonogenic capacity

Migration

Tumorigenic

5a-pregnanos

\author{
Abbreviations: \\ Allopregnanolone (ALLO) \\ Progesterone (P4) \\ Intra-cerebroventricular (icv) \\ Fetal bovine serum (FBS) \\ Phosphate buffer saline (PBS) \\ $5 \alpha$ - dihydroprogesterone ( $5 a \mathrm{DHP})$ \\ 3a-hydroxysteroid oxido-reductase ( $3 \alpha-H S O R$ ) \\ Central nervous system (CNS)
}

\begin{abstract}
Introduction: Ovarian carcinoma is one of the most common cause of death by gynecologic cancer. Several epidemiologic and in vitro studies have shown controversial data about progesterone effects in ovarian cancer. Progesterone can be converted in its active metabolite, allopregnanolone, its effects in ovarian cancer are still unkown. Previously, we demonstrated that allopregnanolone modifies ovarian morphophysiology, being able to alter critical process of tumor development such as proliferation, apoptosis and angiogenesis. Taking into account these antecedents, we investigated the effect of progesterone and allopregnanolone on proliferation, apoptosis, clonogenic capacity and migration on two epithelial human ovarian cancer cell lines, IGROV-1 and SKOV-3.
\end{abstract}

Materials and methods: IGROV-1 and SKOV-3 cells were exposed to a range of progesterone and allopregnanolone concentrations $\left(10^{-11}\right.$ to $\left.10^{-5} \mathrm{M}\right)$ for $72 \mathrm{~h}$.

Proliferation was analyzed by MTT and Ki67 expression. Apoptosis was measured by immunocytochemistry of cleaved caspase 3 . Clonogenic capacity was evaluated by counting colonies. Migration was analyzed by wound assay. 
Results: We showed that allopregnanolone increased proliferation in a concentration dependent manner with respect to control on IGROV-1 and it also enhanced Ki67 expression. Expression of cleaved caspase 3 did not change in any cell line studied. IGROV-1 clonogenic capacity was also increased by allopregnanolone treatment. Both steroids, progesterone and allopregnanolone, increased IGROV-1 migration in a concentration dependent manner. Interestingly none of the steroids tested modified SKOV-3 progression steps.

Conclusion: This is the first evidence that allopregnanolone, a progesterone metabolite, affects tumor progression of human epithelial ovarian cancer. These results could have an impact in the future in clinic diagnosis, prognosis and treatment of ovarian cancer patients. The regulation of progesterone and allopregnanolone steroideogenesis and their molecular mechanisms arise from this work as new possible therapeutic alternatives.

\section{Introduction}

Ovarian cancer is the most lethal form of gynecological neoplasia and the fifth leading cause of death in women's cancer. Approximately, $80-90 \%$ of ovarian tumors present an epithelial origin and are usually diagnosed in metastatic stages with poor survival rates. They are highly heterogeneous and can be classified according to histological subtypes: high- and low-grade serous, clear cell, endometroid, mucinous and undifferenciated cells. Each of these subtypes are associated with different responses to chemotherapy, patterns of metastasis and survival. Surgery and chemotherapy based in paclitaxel or carboplatin have been the standard therapies since past two decades. At this moment, epidemiological and in vitro evidences on progesterone (P4) in ovarian cancer are controversial, which may explain why clinical studies have not shown improvement in patients [1-3]. Examples of this are, an increased incidence of ovarian cancer in women with progesterone defiency, while overexpression of P4 receptor is associated with a worse recurrence-free survival and augmented P4 serum levels in smoking patients are related with a poor prognosis [ 4, 5]. In addition, there are many in vitro studies where P4 binds to different receptors associated with antiapoptotic or pro-apoptotic pathways [6-9]. Therefore, it is necessary to clarify its function and mechanism.

In breast cancer, P4 derivatives could have anti-tumor (4-pregnenes) or pro-tumor (5apregnanes) effects [10]. P4 is converted directly into the derivatives 4-pregnanes and $5 \alpha$-pregnanes like $5 \alpha$ - dihydroprogesterone $(5 \alpha-D H P)$ by the irreversible action of $5 a-$ 
reductase. Then, 5a-DHP could be converted, in a reversible manner, in allopregnanolone (ALLO, 3a-hydroxy-5a-pregnan-20-one or 3a-5atetrahydroprogesterone) by the $3 \alpha$-hydroxysteroid oxido-reductase (3a-HSOR). Tumorigenic breast tissues and breast cancer cell lines have higher concentration of $5 a-D H P$ than normal ones [11]. Besides, 5a-DHP stimulates the proliferation in breast cancer lines [12].

ALLO has been mostly studied in the central nervous system (CNS), as an active derivative of progesterone. However, ALLO is synthesized in the CNS, as well as in the peripheral glands (adrenal and ovary). Previous studies demonstrated that ALLO increases in situations of acute stress and generates negative mood changes related to menstruation and menopause $[13,14]$. In fact, it is known that the concentration of ALLO and P4 varies during the estrous cycle and pregnancy in a similar manner. We have reported that intra-cerebroventricular (ICV) administration of ALLO modulates the hypothalamic-pituitary-gonadal axis and induces morpho-physiological changes at the ovarian level [15-18]. ALLO induces a reduction in nuclear proliferation cell antigen expression, accompanied by an increase in apoptosis of granulosa cells stimulating follicular atresia. On the other hand, ALLO increases the number of old corpora lutea with an inhibition of apoptosis and an increase in angiogenesis [19]. These alterations in follicles and corpora lutea led us to hypothesize that ALLO may also be involved in carcinogenesis, where proliferation, apoptosis and angiogenesis play a critical role [20, 21].

Taking into account the previous findings, it is important to elucidate the role of ALLO in ovarian cancer, which is still unknown. We hypothesize that P4 and/ or its active metabolite (ALLO) can affect tumor progression. The purpose of this study was to analyze the effect of P4 and ALLO on proliferation, apoptosis, clonogenic capacity and migration on epithelial cell lines of ovarian cancer. Here we provide the first evidence that ALLO is involved in ovarian cancer progression.

\section{Materials and methods}

\subsection{Cell Culture}

The human ovarian carcinoma cell lines IGROV-1 and SKOV-3 were purchased from the American Type Culture Collection (ATCC; Manassas, USA), IGROV-1 is sensitive to cis-platinum treatment; histological diagnosis was of an ovarian epithelioma with multiple differentiations, endometroid, with some serous clear cells and undifferentiated foci [22]. SKOV-3 is derived from cis-platinum resistant patient and it was classified as 
an ovarian serous carcinoma [23]. Both cell lines were cultured in RPMI medium (Invitrogen Inc., Carlsbad, CA, USA) with $2 \mathrm{mM}$ L-glutamine, $80 \mu \mathrm{g} / \mathrm{ml}$ gentamicin, 50 $\mathrm{UI} / \mathrm{ml}$ penicilin supplemented with $10 \%$ fetal bovine serum (FBS; Internegocios, Argentina) at $37^{\circ} \mathrm{C}$ in a humidified $5 \% \mathrm{CO} 2$ air.

Cell lines were detached using $0.25 \%$ trypsin and $0.02 \%$ EDTA in $\mathrm{Ca} 2+$ and $\mathrm{Mg} 2+$ free phosphate buffer saline (PBS) in sub confluent monolayers. The medium was replaced three times a week. Cell viability was assayed by Trypan blue exclusion test, and the absence of mycoplasma was confirmed by Hoechst staining.

\subsection{Cell Proliferation Assay}

Growth in vitro studies were conducted using the soluble tetrazolium salt MTS colorimetric assay (Cell Titer 96TM AQueous Non-Radioactive Cell Proliferation Assay, Promega, Madison, WI, USA). MTS couples fenazine methylsulfate (PMS) and is reduced to formazan. Both cell lines were seeded in 96-well microplates at a density of 5000 cells per well in RPMI medium supplemented with 5\% FBS. After $24 \mathrm{~h}$, cells were deprived of FBS to induce quiescence ( $24 \mathrm{~h}$ previous to the proliferation assay) and were treated with increasing concentrations of P4 or ALLO $\left(10^{-11}-10^{-5} \mathrm{M}\right)$ by sextuplicate during $72 \mathrm{~h}$. Later, the medium was replaced with $100 \mu \mathrm{l}$ of fresh medium containing $20 \mu \mathrm{MTS}$ : PMS (20: 1), and after $2 \mathrm{~h}$ of incubation at $37^{\circ} \mathrm{C}$, the production of formazan was evaluated by measuring the absorbance at $490 \mathrm{~nm}$ with an ELISA reader (Bio-Rad Laboratories, Inc. Oakland, CA, USA). Three independent experiment were made; and the mean absorbance value of the sextuplicate samples \pm SEM were calculated for each experiment. Results were expressed as a percentage of stimulation in relation to control (cells without treatment). Moreover, alive and dead cells were analyzed through direct cell count with trypan blue [25].

\subsection{Immunocytochemistry}

Cells were growing cultured on glass coverslips, treated and fixed in $4 \%$ formaldehyde for $15 \mathrm{~min}$ and permeabilized with $0.5 \%$ Triton X-100 for $5 \mathrm{~min}$ as described by CuelloCarion et al. 2015 [26]. Fixed cells were incubated with the primary antibodies overnight at $4{ }^{\circ} \mathrm{C}$ in humidity chambers; we use a monoclonal mouse anti KI67 antibody (DAKO, Carpinteria, CA, USA; 1:100); and a rabbit polyclonal antibody against Caspase 3 (Abcam, ABCAM, Cambridge, Reino Unido; 1:400). A commercial kit to detect mouse and rabbit primary antibodies was used [Dako EnVision System, horse radish peroxidase, diaminobenzidine (DAB), from Dako, Carpinteria, CA, USA]. Coverslips were slightly counterstained with hematoxylin to reveal nuclei, examined 
and photographed with a Nikon Eclipse E200 microscope (Japan). Non-specific mouse IgG1 antibody and purified rabbit pre-immune serum (DAKO, Kingsgrove, NSW, Australia) were used as isotype negative controls. The percentage of proliferative or apoptotic cells was determined by counting 200 cells per area. Three independent experiments were made by triplicate and mean \pm SEM were calculated for each experiment. Results were expressed as the percentage of stimulation in relation to control (cells without treatment).

\subsection{Colony Formation Assay}

Cells were cultured in a 6 -well plate and after $48 \mathrm{~h}$ were exposed to various concentrations of P4 or ALLO $\left(10^{-11}, 10^{-8}\right.$ y $\left.10^{-5} \mathrm{M}\right)$ for $72 \mathrm{~h}$. Later, a suspension containing 100-1000 cells was plated in 6 well culture dishes for clonogenic assay. The cells were then incubated for 14 days at $37^{\circ} \mathrm{C}$ with $5 \% \mathrm{CO}_{2}$. The colonies were fixed by cold methanol, stained with $1 \%$ violet crystal in ethanol and then counted. Colonies with more than 30 cells were considered positive. Three independent experiments were made. The results were expressed as the mean of absorbance value of the triplicate samples \pm SEM, and expressed as the percentage of clonogenic efficiency in relation to control (cells without treatment).

\subsection{Migration assay.}

IGROV-1 or SKOV-3 cells were seeded in 24 -well plates at a density of $2 \times 10^{5}$ cells/well in RPMI with $5 \%$ FBS. After $24 \mathrm{~h}$, under subconfluency conditions (90\%), cells were deprived of SFB by $24 \mathrm{~h}$ and they were treated with increasing concentrations of P4 or ALLO for $72 \mathrm{~h}$ in starvation conditions until finish assay. A wound of $4 \mu \mathrm{m}$ wide was made on the monolayer, washed with PBS and photographed at regular intervals during $24 \mathrm{~h}$. The area covered was calculated by comparing the area to time zero, with respect to the selected time interval. The covered area was integrated with image $\mathrm{J}$ software $(\mathrm{NIH})$. Three independent experiments were made. Results were expressed as a percentage of migration in relation to the migration of cells without treatment considered as $100 \%$ [27].

\subsection{Statistical analysis}

Statistical analyses were performed using the GraphPad Prism 5 (Graphpad software Inc, San Diego, CA). Results are presented as mean \pm SEM of at least three independent experiments. The statistical significance of differences between groups 
was analyzed by One-Way analysis of variance, Tukey's Multiple Comparison Test; $p<0.05$ was considered to be statistically significant.

\section{Results}

\subsection{Effect of progesterone and allopregnanolone on human ovarian tumor cells proliferation assay.}

The effects of P4 and ALLO on proliferation of ovarian cancer cell lines IGROV-1 and SKOV-3 were analyzed using three diferent methods (MTS assay, trypan blue dye exclusion and Ki67 expression). Viability was evaluated using concentration-response curves that covered a range from $10^{-11}$ to $10^{-5} \mathrm{M}$ for each steroid. As shown in Fig. $1 \mathrm{~A}$ and 1B, P4 did not modify proliferation in any of the cell lines studied. The ALLO proliferacion curve has a similar patherns to a biphasic one. ALLO effect was significantly different with respect to the control in a range of $10^{-8}$ to $10^{-5} \mathrm{M}$. The maximal effect concentration was $10^{-5} \mathrm{M}$, the highest concentration tested (44.5 \pm 13.5 $\%$ proliferation respect to control; $p<0.001)$ and in the lowest concentration tested $\left(10^{-11}\right.$ $M ; p<0.001$ ), where the percentage of proliferation was increased by $38.6 \pm 16 \%$ ( $p<0.001 ;$ ALLO vs control).

ALLO did not modify the proliferation of SKOV-3.

Trypan blue assay showed an increase in living cells only after ALLO treatment on IGROV-1 cells, in a similar manner to MTS assay (data not shown).
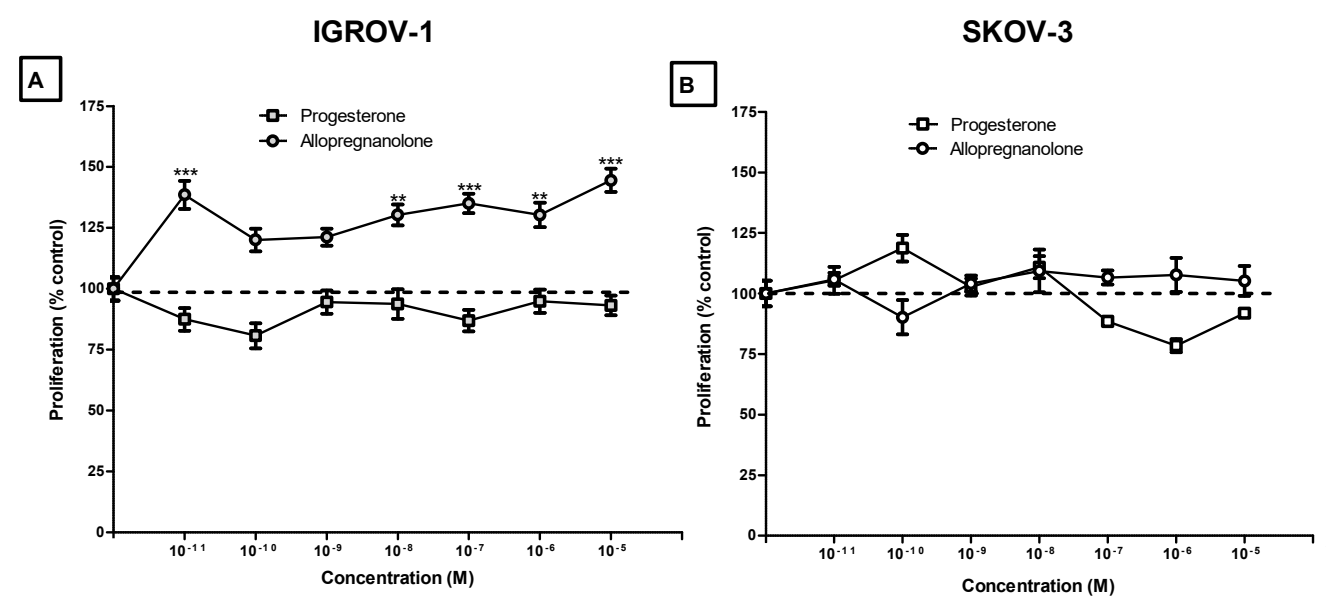

Fig. 1. Effect of progesterone or allopregnanolone on ovarian cancer cells proliferation. Concentration-response curves of progesterone or allopregnanolone on (A) IGROV-1 or (B) SKOV-3 cells proliferation. Values are expressed as mean \pm SEM of three independent experiments performed in sixfold. ${ }^{* *} p<0.01 ;{ }^{* * *} p<0.001$ ALLO (M) vs control (cells without treatment). 
Taking these results in consideration, the next step was to elucidate whether ALLO modulation on cell growth was associated with a modification on IGROV-1 cell proliferation and/or cell death. For that purpose, the expression of the proliferation marker Ki67 was assessed by immunostaining on treated cell monolayers. The number of Ki67 positive cells was augmented after ALLO treatment in IGROV-1 cells (Fig. 2A), whereas no difference was detected on SKOV-3 cells (Fig. 2B).
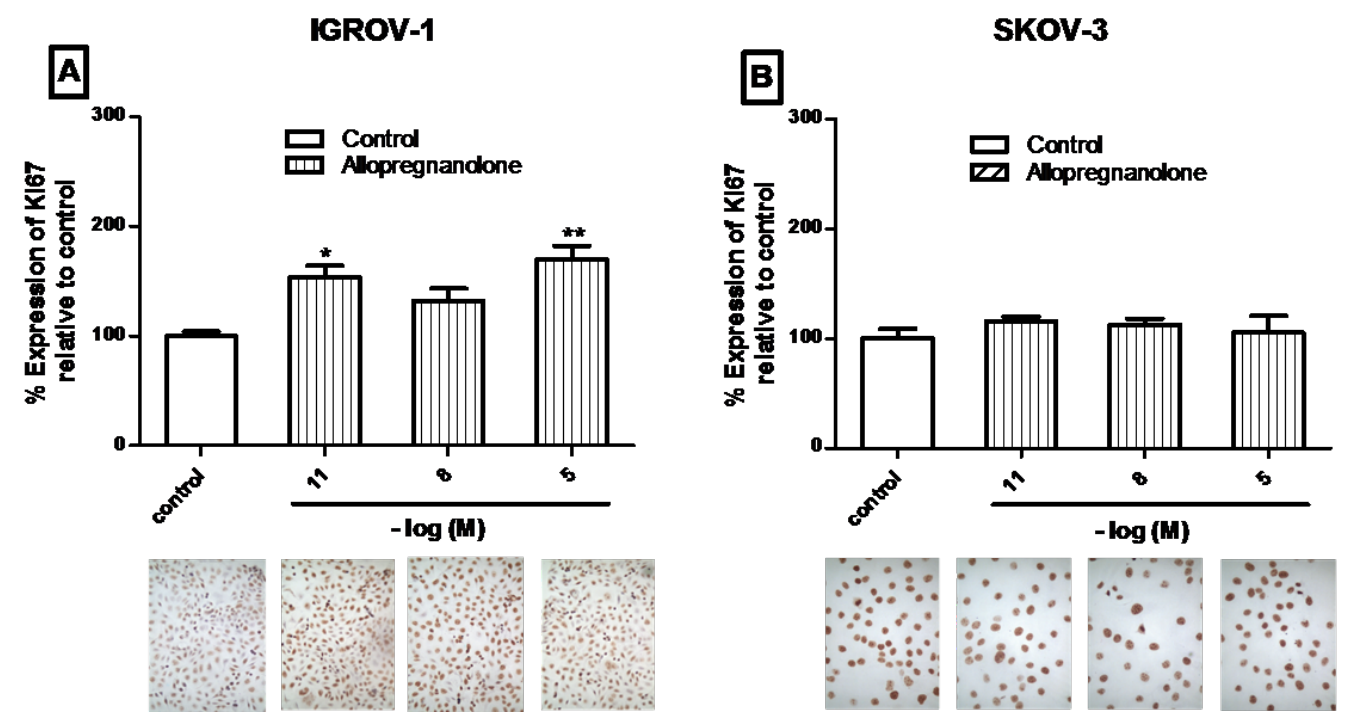

Fig.2 Ki67 expression after allopregnanolone treatement on A) IGROV-1 and B)

SKOV-3 cells. Graphs correspond to quantification of Ki67+ cells, relative to untreated cells as control. The images shown are representative, taken with a $4 x$ magnification and correspond to the treatments indicated in the bar diagram. Values are expressed as mean \pm SEM of three independent experiments performed in triplicate. ${ }^{*} p<0.05$; ${ }^{* *} p<0.01$ ALLO (M) vs control (cells without treatment).

\subsection{Effect of allopregnanolone on human ovarian tumor cells apoptosis.}

To analyze the effect of ALLO on cell death, the expression of cleaved caspase 3 was studied. ALLO did not affect apoptosis with the tested concentrations $\left(10^{-11} \mathrm{M}, 10^{-8} \mathrm{M}\right.$ y $10^{-5} \mathrm{M}$ ) on both cell lines studied (Fig. 3). 


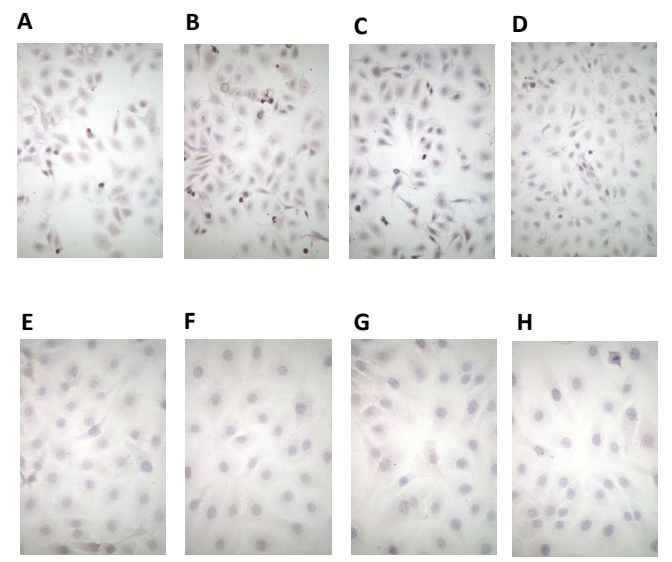

Fig.3: Cleaved caspase 3 expression after allopregnanolone treatment on A-D) IGROV-1 and E-H) SKOV-3 cells. The images shown are representative, taken with a $4 \mathrm{X}$ magnification and correspond to $\mathrm{A}, \mathrm{E})$ control and the treatments with allopregnanolone $\left.B, F) 10^{-11} \mathrm{M}, \mathrm{C}-\mathrm{G}\right) 10^{-8} \mathrm{M}$ y $\left.\mathrm{D}, \mathrm{H}\right) 10^{-5} \mathrm{M}$. Values are expressed as mean \pm SEM of three independent experiments performed in triplicate.

\subsection{Effect of progesterone and allopregnanolone on human ovarian tumor cells} clonogenic capacity.

To study long-term the effects of P4 and ALLO on IGROV-1 and SKOV-3 cells, colony formation assays were performed. Ovarian tumor cells were treated with increasing concentrations of P4 or ALLO for $72 \mathrm{~h}$, and then, harvested and replate as a monocellular suspension. The cells were then allow to grow for fourteen days to investigate their colony formation ability. Whereas P4 did not modify the clonogenic capacity of IGROV-1 and SKOV-3 cells (Fig. 4A and 4B), Fig. 4C shows that ALLO induced a significant increase in the number of IGROV-1 cell colonies compared with the untreated cells. As expected, ALLO did not affect the clonogenic capacity on SKOV-3 cells (Fig. 4D). 
A

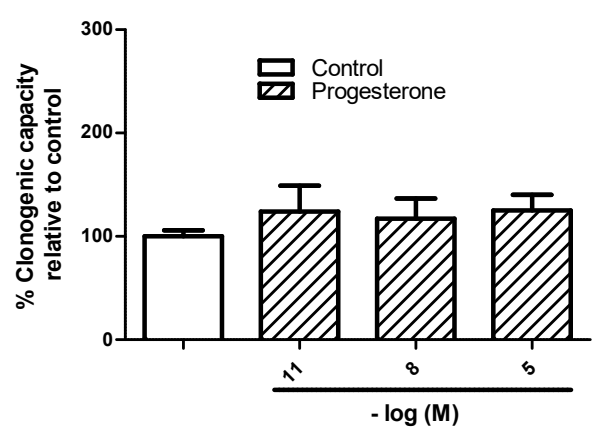

C

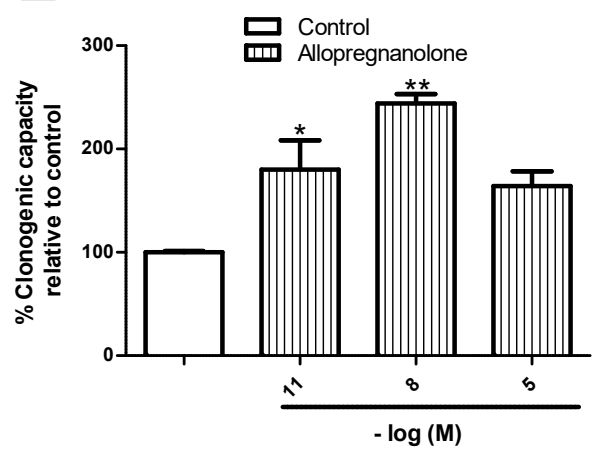

B

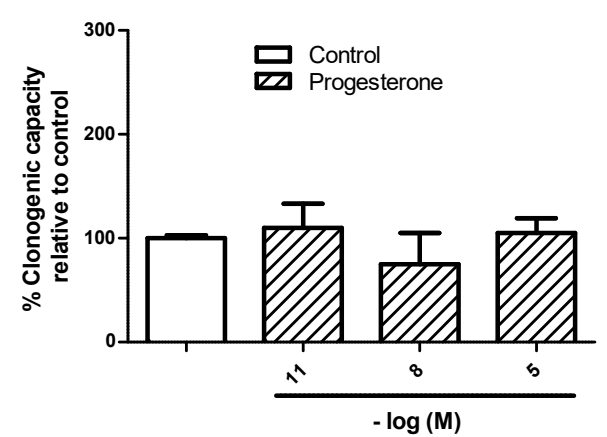

D

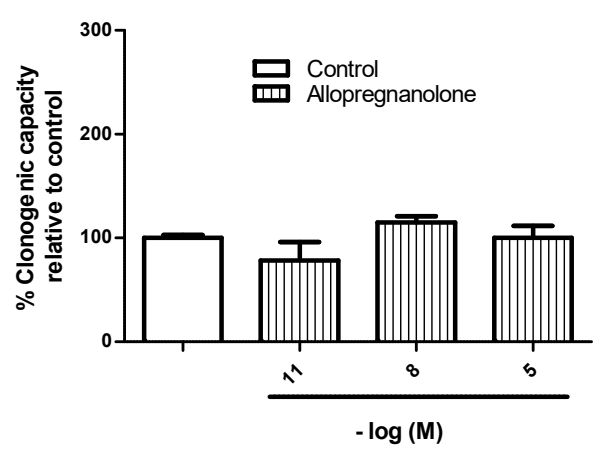

Fig. 4. Effect of progesterone or allopregnanolone on (A and C) IGROV-1 and (B and D) SKOV-3 cells clonogenic capacity. Values are expressed as mean \pm SEM of three independent experiments performed in triplicate. ${ }^{*} p<0.05 ;{ }^{* *} p<0.01$; ALLO vs control (cells without treatment).

\subsection{Effect of progesterone and allopregnanolone actions on human ovarian} tumor cells migration.

A classical in vitro wound healing assay was used to measure the migration rate of ovarian tumor cells IGROV-1 and SKOV-3 after treatment with P4 and ALLO. Both steroids significantly increased the wound healing ability of IGROV-1 cells, in a concentration-dependent manner, compared with the untreated controls. The maximal effective concentration of P4 and ALLO were $10^{-11} \mathrm{M}$ (the lower tested), that increased cell migration by a maximum $148 \pm 14 \%$ and $175 \pm 21 \%$ respectively (Fig $5 \mathrm{~A}$ ). None of the steroids tested modified the migration of SKOV-3 cells (Fig 5B). 
IGROV-1

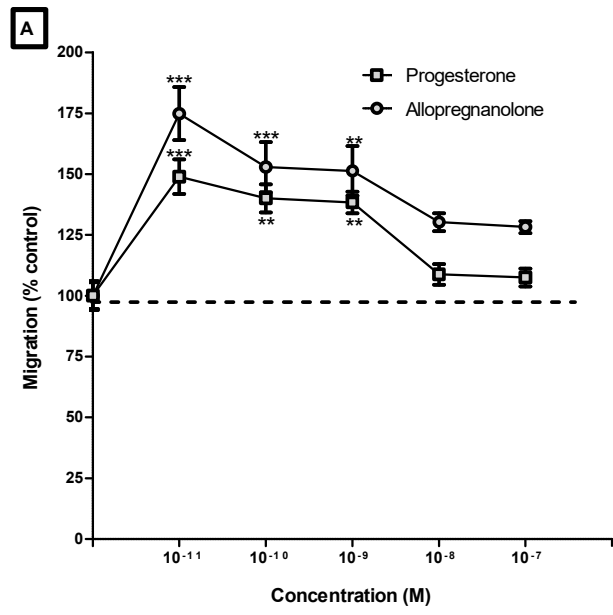

SKOV-3

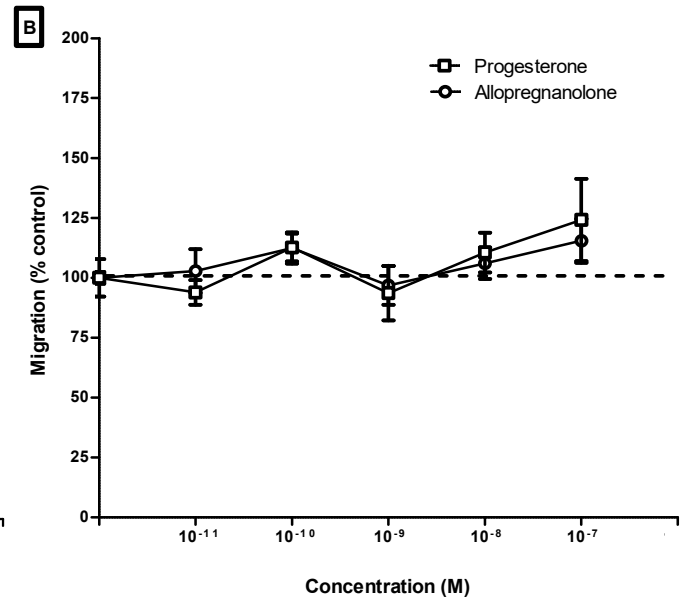

Fig. 5. Concentration-response curves of progesterone or allopregnanolone on

(A) IGROV-1 and (B) SKOV-3 cells migration. Values are mean \pm SEM of three independent experiments performed in quadruplicate. ${ }^{* *} \mathrm{p}<0.01 ;{ }^{* * *} \mathrm{p}<0.001$ progesterone/allopregnanolone (M) vs control (cells without treatment).

\section{DISCUSSION}

Tumor progression involves a several process that allow growth and metastasis formation. P4 presents a complex mechanism of action, which is not entirely clear, and that once metabolized produces active compounds that may also regulate physiological or pathological processes, such us ovarian cancer. In the current work, we investigated the effect of P4 and ALLO over some biological process related with tumor progression and present the first evidence that ALLO can regulate the progression of epithelial ovarian cancer.

In this work it was evaluated: proliferation, apoptosis, clonogenic capacity and migration on human ovarian cancer cells. Under physiological conditions, the balance between proliferation and apoptosis remains closely regulated, thus ensuring the integrity of tissues and organs. Tumoral transformation interferes with the control of these processes, causing the uncontrolled division of malignant cells [28]. In this investigation, P4 did not affect proliferation but its metabolite, ALLO, stimulated IGROV-1 cells proliferation in a concentration-dependent manner. We found that in this cell line, ALLO produced an increase in viability at physiological $\left(10^{-11} \mathrm{M}\right)$ as well as at higher $\left(10^{-5} \mathrm{M}\right)$ concentrations $(p<0.001)$ [29]. These results were corroborated by Trypan Blue. Besides, we evaluated the action of ALLO over proliferation expression 
markers and, as expected, ALLO enhanced ki67 only on IGROV-1 cells. At the same time, ALLO did not change cleaved caspase 3 expression neither IGROV-1 nor SKOV3 cells. In accordance with our results, Zamora-Sanchez et al. (2017) [30] found that ALLO increases the number of tumor cells derived from glioblastoma by the regulation of genes involved in tumor progression. In turn, Shepelin et al. (2016) [31] demonstrated the existence of a relationship between melanoma progression and ALLO biosynthesis; this study was made with transcriptional data using computational tools. Moreover, in breast cancer cell lines, Xu et al. (2016) [32] showed that steroidogenesis stimulation increase the levels of ALLO and tumoral cell proliferation. Also, patients with breast cancer have high level of ALLO in cyst fluid [33]. Wiebe et al. (2000 and 2006) [12, 34] showed that an increase in 5a-pregnanes (which can serve as precursor to ALLO) promoted cell proliferation and detachment in breast cancer cell lines. These studies together with ours show the importance of considering the active metabolites of P4, in particular ALLO, as well as the regulation of their synthesis, in the progression of cancer.

Peluso et al. (2009) [9] showed that P4 $\left(10^{-6}\right.$ o $\left.10^{-9} \mathrm{M}\right)$ did not change the apoptotic nuclei percentage on SKOV-3 cells. In vitro studies has shown that P4 has a dual effect, inhibiting or stimulating apoptosis. P4 induces apoptosis through classical progesterone receptors in several ovarian cancer cell lines [6, 7]. On the other hand, P4 protect ovarian cancer cells from the apoptotic effect produced by cisplatin, allowing the restoration to their proliferative and migratory capacity. These anti-apoptotic effect was mediated by the component 1 of the membrane P4 1/ 2 receptors (PGRMC1/2) through P3IK / AKT pathway [8, 9]. Prove that different action of this progestagens, could be a consequence of the differential expression of receptors or mediator signals.

Furthermore, we analyzed cellular sensitivity of P4 or ALLO on the clonogenic capacity of both cell lines. Our results show that $72 \mathrm{~h}$ of $\mathrm{P} 4$ treatment did not modify the ability to form colonies in any of the cell lines studied. At the same time, McDonnel et al. (2003) [35] evidenced that P4 decreases membrane fluidity and inhibited colony formation (after 14 days treatment) in SKOV-3 cells. Even though there are evidence that P4 might inhibit colony formation in SKOV-3 cells (35), it is known that the effects of progestagens varies according to the duration of treatment. ALLO increased clonogenic capacity only in IGROV-1 tumoral cells. This is consistent with the ability of this steroid to stimulate tumor proliferation in this cell line. The present evidence about 
steroids show, once again, the great complexity of its mechanism of action that not only depends on the concentration of these steroids but also on the time of its exposure.

The metastatic process comprehends multiple steps, but migration has a critical role, allowing cells to reach blood vessels. Progestagens are involved in migration and invasion changes of breast cancer cells through alterations in the actin cytoskeleton [36]. In this work, P4 and ALLO enhanced IGROV-1 migration in a concentrationdependent manner but had no effect on SKOV-3 migration. On IGROV-1, P4 and ALLO produced the maximum effect at the lowest concentration $\left(10^{-11} \mathrm{M} ; \mathrm{p}<0.001\right)$ that decreased until it became non-significant for higher concentrations. In accordance with our results, Fu et al. (2008) [36] observed that P4 stimulated cellular migration and invasion through a reorganization of the cytoskeleton, formation of pseudopodia and membrane extensions in a breast cancer cell line. Besides, Fu et al. (2010) [37] showed that P4 generates the phosphorylation of FA kinase (FAK) which increases migration of breast cancer cells. Interestingly, this enzyme has also been related with metastatic behavior in ovarian cancer [38]. It is important to highlight that it is the first report of ALLO regulating the tumor migration that could be involved in metastasis development of epithelial ovarian cancer.

Until now, there were no reports of ALLO being involved in the regulation of tumor migration. Recently, this metabolite was found to be involved in physiological processes, development, maturation and regeneration of Schwann cells activating both proliferation and migration, through the modulation of the Src / FAF signaling pathway and actin rearrangements [39]. These antecedents cited above, including works where ALLO regulates tumor proliferation, clearly show that this metabolite has effects in itself and may affect tumor development.

The contradictory results of P4 found in the literature may be caused by diverse factors. Many authors have shown time and concentration dependent effects, which are able to modulate apoptosis. Here, lower ALLO concentrations stimulated proliferation and migration; and higher ALLO concentrations only increased proliferation on IGROV-1. Also, the different effect observed on both cell lines could be due to the action of P4 or ALLO on different receptors. Further experiments are needed to identify the different molecular mechanism involved in P4 or ALLO response on IGROV-1 that have not yet been characterized. Based on current evidence, ours and from other authors, we believe that the response could be related to pro-tumor or/and 
anti-tumor effects generated by P4 or its metabolites, and the effects of these steroids on different receptors.

Our results contribute to clarify the action of P4 and its metabolite, ALLO, involved on ovarian cancer, which could lead to new alternatives for prevention, diagnosis or treatment. In a breast cancer in vivo e in vitro model, P4 stimulated tumorigenesis and this effect was blocked by finasteride (5a-reductase inhibitor) [40]. Moreover, dutasteride (another 5a-reductase inhibitor) was studied in clinical trials, with good effects on the regulation of ALLO levels and symptoms associated with menopausal syndrome [41]. We believe that therapeutic tools associated with the regulation of P4 metabolism could be proposed by patients with ovarian cancer, such as blocking the enzyme 5a-reductase and, in turn, lowering ALLO levels; as well as blocking ALLO binding to its receptors or lowering its expression.

\section{Summary and conclusions}

P4 stimulated migration on IGROV-1 cells, and its metabolite, ALLO, enhanced proliferation, clonogenic capacity and migration in this cell line. Neither P4 nor ALLO modify progression on SKOV-3 cells.

These findings are important to clarify the role of P4 in ovarian cancer and are the first evidence of ALLO, an active metabolite of P4, affecting tumor progression of cells derived from human ovarian epithelial tumors. These results may have therapeutic implications for patients which might benefit from the blockage of their action or the regulation of tumor steroidogenesis.

\section{Acknowledgments}

Special thanks to PhD. Rubén W. Carón, PhD. Mariel Fanelli, PhD Matias Sanchez and PhD. Elisa Bal de Kier Joffé, for their kind collaboration and contribution. Also to Mercantil Andina for the donation to this research and to CONICET for institutional support and wages.

\section{Conflicts of interest}

The authors declare no competing financial interests.

\section{Grant support}

This work was supported by the PUE 0074 CONICET, Universidad of Mendoza granted to Pelegrina LT (2017-2019) y Universidad Maza of Pelegrina LT (2018). 


\section{References}

[1] Jemal A, Siegel R, Ward E, Hao Y, Xu J, Thun MJ. 2009. Cancer statistics. CA Cancer J Clin. 59:225-249.

[2] Cho KR, Shih le M. 2009. Ovarian cancer. Annu Rev Pathol. 4:287-313.

[3] Salzberg M, Thurlimann B, Bonnefois $\mathrm{H}$, et al. 2005. Current concepts of treatment strategies in advanced or recurrent ovarian cancer. Oncology. 68: 293-298.

[4] Modan B, Ron E, Lerner-Geva L, Blumstein T, Menczer J, Rabinovici J, Oelsner G, Freedman L, Mashiach S, Lunenfeld B. 1998. Cancer incidence in a cohort of infertile women. Am J Epidemiol. 147:1038-42.

[4] Jatoi A, Vierkant RA, Hawthorne KM, Block MS, Ramus SJ, Larson NB, Fridley BL, Goode EL. 2016. Clinical and Emergent Biomarkers and Their Relationship to the Prognosis of Ovarian Cancer. Oncology. 90:59-68. doi: 10.1159/000442710.

[5] O'Brien ME1, Dowsett M, Fryatt I, Wiltshaw E. 1994. Steroid hormone profile in postmenopausal women with ovarian cancer. Eur J Cancer.30(4):442-5.

[6] Syed V, Mukherjee K, Godoy-Tundidor S, Ho SM. 2007. Progesterone induces apoptosis in TRAIL-resistant ovarian cancer cells by circumventing C-FLIPL overexpression. J Cell Biochem.102(2):442-52.

[7] Nguyen H, Syed V. 2011. Progesterone inhibits growth and induces apoptosis in cancer cells through modulation of reactive oxygen species. Gynecol Endocrinol. 27(10):830-6.

[8] Zhu X, Han Y, Fang Z, Wu W, Ji M, Teng F, Zhu W, Yang X, Jia X, Zhang C. 2013. Progesterone protects ovarian cancer cells from cisplatin-induced inhibitory effects through progesterone receptor membrane component $1 / 2$ as well as AKT signaling. Oncol Rep. 30(5):2488-94.

[9] Peluso JJ, Gawkowska A, Liu X, Shioda T, Pru JK. 2009. Progesterone receptor membrane component-1 regulates the development and Cisplatin sensitivity of human ovarian tumors in athymic nude mice. Endocrinology. 150(11):4846-54.

[10] Wiebe JP. 2005. Role of progesterone metabolites in mammary cancer. J Dairy Res.72:51-7.

[11] Wiebe JP, Zhang G, Welch I, Cadieux-Pitre HA. 2013. Progesterone metabolites regulate induction, growth, and suppression of estrogen- and progesterone receptornegative human breast cell tumors. Breast Cancer Res.15(3):R38.

[12] Wiebe JP, Muzia D, Hu J, Szwajcer D, Hill SA, Seachrist JL. 2000. The 4pregnene and 5alpha-pregnane progesterone metabolites formed in nontumorous and 
tumorous breast tissue have opposite effects on breast cell proliferation and adhesion. Cancer Res. 60(4):936-43.

[13] Bernardi F, Pluchino N, Begliuomini S, Lenzi E, Palumbo M, Luisi M, Genazzani AR. 2004. Disadaptive disorders in women: allopregnanolone, a sensitive steroid. Gynecol Endocrinol.19(6):344-53.

[14] Bäckström T1, Bixo M2, Johansson M2, Nyberg S2, Ossewaarde L3, Ragagnin G2, Savic 14, Strömberg J2, Timby E2, van Broekhoven F2, van Wingen G5. 2014. Allopregnanolone and mood disorders. Prog Neurobiol. 113:88-94.

[15] Laconi MR, Casteller G, Gargiulo PA, Bregonzio C, Cabrera RJ.. 2001. The anxiolytic effect of allopregnanolone is associated with gonadal hormonal status in female rats. Eur J Pharmacol. 417: 111-6.

[16] Laconi MR, Cabrera RJ. 2002. Effect of centrally injected allopregnanolone on sexual receptivity, luteinizing hormone release, hypothalamic dopamine turnover, and release in female rats. Endocrine.17: 77-83

[17] Laconi MR, Chavez C, Cavicchia JC, Fóscolo M, Sosa Z, Yunes RF, Cabrera RJ. 2012. Allopregnanolone alters the luteinizing hormone, prolactin, and progesterone serum levels interfering with the regression and apoptosis in rat corpus luteum. Horm Metab Res. 44: 632-8.

[18] Pelegrina L, Giuliani, F, Cáseres A, Parborell F and Laconi M. 2015. Allopregnanollone affects ovarian and hypothalamic steroidogenesis, folicular development and induces cysts formation in adult rats. Reproduction. Enviado.

[19] Asencio, J, Pelegrina L, Cáseres, A, Caseres A, Parborell F and Laconi M. 2015. Allopregnanollone alters ovarian morpho-phisioogy: effects on apoptosis and angiogenesis. Reproduction. Enviado.

[20] Spencer SJ1, Cataldo NA, Jaffe RB. 1996. Apoptosis in the human female reproductive tract. Obstet Gynecol Surv. 51(5):314-23.

[21] Lombardi MG1, Negroni MP, Pelegrina LT, Castro ME, Fiszman GL, Azar ME, Morgado CC, Sales ME. 2013. Autoantibodies against muscarinic receptors in breast cancer: their role in tumor angiogenesis. PLoS One. 8(2):e57572

[22] Bénard J, Da Silva J, De Blois MC, Boyer P, Duvillard P, Chiric E, Riou G. 1985. Characterization of a human ovarian adenocarcinoma line, IGROV1, in tissue culture and in nude mice. Cancer Res. 45(10):4970-9.

[23] Beaufort CM1, Helmijr JC, Piskorz AM, Hoogstraat M, Ruigrok-Ritstier K1, Besselink N, Murtaza M, van IJcken WF, Heine AA, Smid M, Koudijs MJ, Brenton JD, Berns EM, Helleman J. 2014. Ovarian cancer cell line panel (OCCP): clinical importance of in vitro morphological subtypes. PLoS One. 9(9):e103988. 
[24] Hua W, Christianson T, Rougeot C, Rochefort H, Clinton GM. 1995. SKOV3 ovarian carcinoma cells have functional estrogen receptor but are growth-resistant to estrogen and antiestrogens. J Steroid Biochem Mol Biol. 55(3-4):279-89

[25] Negroni MP, Fiszman GL, Azar ME, Morgado CC, Español AJ, Pelegrina LT, de la Torre E, Sales ME. 2010. Immunoglobulin G from breast cancer patients in stage I stimulates muscarinic acetylcholine receptors in MCF7 cells and induces proliferation. Participation of nitric oxide synthase-derived nitric oxide. J Clin Immunol. 30(3):474-84. [26] Cuello-Carrión, F.D., Shortrede, J.E., Alvarez-Olmedo, D., Cayado-Gutiérrez, N., Castro, G.N., Zoppino, F.C., Guerrero, M., Martinis, E., Wuilloud, R., Gómez, N.N. and Biaggio, V., 2015. HER2 and $\beta$-catenin protein location: importance in the prognosis of breast cancer patients and their correlation when breast cancer cells suffer stressful situations. Clinical \& experimental metastasis, 32(2), 151-168.

[27] Pelegrina LT, Lombardi MG, Fiszman GL, Azar ME, Morgado CC, Sales ME. 2013. Immunoglobulin $\mathrm{g}$ from breast cancer patients regulates MCF-7 cells migration and MMP-9 activity by stimulating muscarinic acetylcholine receptors. J Clin Immunol. 33(2):427-35.

[28] Hanahan, D. and Weinberg, R.A. 2000. The hallmarks of cancer. Cell, 100(1): 5770.

[29] Purdy RH1, Moore PH Jr, Rao PN, Hagino N, Yamaguchi T, Schmidt P, Rubinow DR, Morrow AL, Paul SM. Radioimmunoassay of 3 alpha-hydroxy-5 alpha-pregnan-20one in rat and human plasma. Steroids. 1990 Jul; 55(7):290-6.

[30] Zamora-Sánchez CJ, Hansberg-Pastor V, Salido-Guadarrama I, RodríguezDorantes M3, Camacho-Arroyo I. 2017. Allopregnanolone promotes proliferation and differential gene expression in human glioblastoma cells. Steroids. 119:36-42.

[31] Shepelin, D., Korzinkin, M., Vanyushina, A., Aliper, A., Borisov, N., Vasilov, R., Zhukov, N., Sokov, D., Prassolov, V., Gaifullin, N. and Zhavoronkov, A., 2016. Molecular pathway activation features linked with transition from normal skin to primary and metastatic melanomas in human. Oncotarget, 7(1), 656.

[32] Xu JN, Shen D, Mao WD, Lin QF, Lin F, Lu C. 2016. The effects of PK11195 on the MCF-7 and T47D were associated with the allopregnanolone biosynthesis, which was mediated by Translocator Protein $18 \mathrm{KDa}$. Cancer Biomark.17(1):11-6

[33] Bicíková M, Számel I, Hill M, Tallová J, Stárka L. 2001. Allopregnanolone, pregnenolone sulfate, and epitestosterone in breast cyst fluid. Steroids. 66(1):55-7.

[34] Wiebe JP. 2006. Progesterone metabolites in breast cancer. Endocr Relat Cancer. 13(3):717-38. 
[35] McDonnel AC, Van Kirk EA, Isaak DD, Murdoch WJ. 2003. Inhibitory effects of progesterone on plasma membrane fluidity and tumorigenic potential of ovarian epithelial cancer cells. Exp Biol Med (Maywood). 228(3):308-14.

[36] Fu XD, Giretti MS, Baldacci C, Garibaldi S, Flamini M, Sanchez AM, Gadducci A, Genazzani AR, Simoncini T. 2008. Extra-nuclear signaling of progesterone receptor to breast cancer cell movement and invasion through the actin cytoskeleton.

PLoS One. 3(7):e2790.

[37] Fu XD1, Goglia L, Sanchez AM, Flamini M, Giretti MS, Tosi V, Genazzani AR, Simoncini T. 2010. Progesterone receptor enhances breast cancer cell motility and invasion via extranuclear activation of focal adhesion kinase. Endocr Relat Cancer. 17(2):431-43.

[38] Hu XW1, Meng D, Fang J. 2008. Apigenin inhibited migration and invasion of human ovarian cancer A2780 cells through focal adhesion kinase. Carcinogenesis. 29(12):2369-76.

[39] Melfi S, Montt Guevara MM, Bonalume V, Ruscica M, Colciago A, Simoncini T, Magnaghi V. 2017. Src and phospho-FAK kinases are activated by allopregnanolone promoting Schwann cell motility, morphology and myelination. J Neurochem. 141(2):165-178. doi: 10.1111/jnc.13951

[40] Wiebe JP, Rivas MA, Mercogliano MF, Elizalde PV, Schillaci R. 2015. Progesterone-induced stimulation of mammary tumorigenesis is due to the progesterone metabolite, $5 \alpha$-dihydroprogesterone $(5 \alpha \mathrm{P})$ and can be suppressed by the 5a-reductase inhibitor, finasteride. J Steroid Biochem Mol Biol. 149:27-34.

[41] Martinez PE1, Rubinow DR2, Nieman LK3, Koziol DE4, Morrow AL2, Schiller CE2, Cintron D5, Thompson KD1, Khine KK1, Schmidt PJ1. 2016. 5a-Reductase Inhibition Prevents the Luteal Phase Increase in Plasma Allopregnanolone Levels and Mitigates Symptoms in Women with Premenstrual Dysphoric Disorder. Neuropsychopharmacology. 41(4):1093-102. 